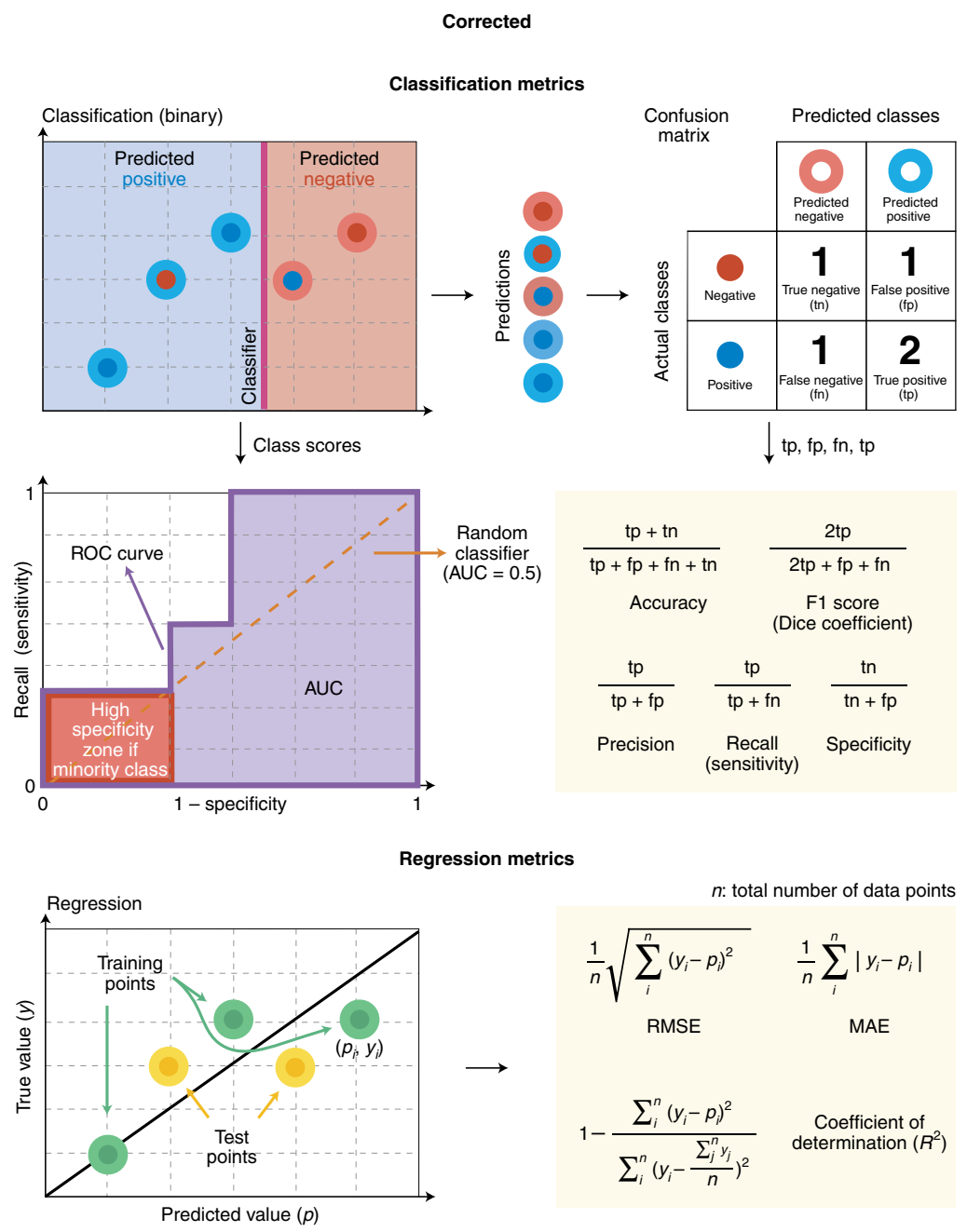

Fig. 2 | Original and corrected.

Published online: 23 September 2021

https://doi.org/10.1038/s41592-021-01304-2

๑) Springer Nature America, Inc. 2021

\title{
Publisher Correction: Deep learning enables fast and dense single-molecule localization with high accuracy
}

Artur Speiser (D), Lucas-Raphael Müller, Philipp Hoess (ID, Ulf Matti ID, Christopher J. Obara, Wesley R. Legant, Anna Kreshuk (D), Jakob H. Macke (D), Jonas Ries (D) and Srinivas C. Turaga (D)

Correction to: Nature Methods https://doi.org/10.1038/s41592-021-01236-x, published online 3 September 2021.

In the version of this Article initially published, Jacob H. Macke and Jonas Ries were not listed as corresponding authors. Their contact information and designation as corresponding authors are now included. The error has been corrected in the online version of the Article.

Published online: 21 September 2021

https://doi.org/10.1038/s41592-021-01305-1

(c) The Author(s), under exclusive licence to Springer Nature America, Inc. 2021 